J.Lake Sci.(湖泊科学), 2016, 28(1): 195-206

DOI 10. 18307/2016. 0123

(C) 2016 by Journal of Lake Sciences

\title{
基于时间序列谐波分析的鄱阳湖湿地植被分布与水位变化响应”
}

\author{
刘旭颖 ${ }^{1,2}$, 关燕宁 ${ }^{1 * *}$, 郭 杉 ${ }^{1}$, 张春燕 ${ }^{1}$, 王 蕾 ${ }^{1,2}$ \\ (1: 中国科学院遥感与数字地球研究所, 北京 100101) \\ (2: 中国科学院大学, 北京 100049)
}

\begin{abstract}
摘 要: 采用高时间分辨率遥感信息的谐波分析方法, 提取反映鄱阳湖湿地植被指数随水位变化的谐波分量, 分别以自 然年和水文年的不同周期作为湿地植被指数谐波分析单元, 利用时间序列信号的最大振幅谐波分量的变化周期表征湿 地植被指数在不同分析单元的变化模式, 结合常年水位观测数据和湿地植被群落在不同物候期的时间与空间特征,探讨 鄱阳湖国家级自然保护区和南矶湿地国家级自然保护区的植被分布面积与水位变化关系.结果表明: (1) 鄱阳湖湿地植 被分布受水文状况影响的特征明显, 相对于南矶自然保护区, 鄱阳湖自然保护区湿地植被分布面积对观测水位的变化更 为敏感. (2) 两个自然保护区范围内的湿地植被分布面积与对应水文年 9 和 10 月的观测水位呈现较强的负相关关系, 且 在 0.05 水平上显著.一年两季生长的湿地植被分布面积受退水时间影响大于次年的涨水时间, 与枯水期的观测水位无明 显的相关关系. (3) 两个自然保护区在不同高程区间的湿地植被分布面积与观测水位的相关关系和显著性呈现各自特 征. 在鄱阳湖保护区, 12 13 $\mathrm{m}$ 高程区间的湿地植被分布面积与 9 月观测水位的相关性最强, 且相关关系在 0.05 水平上显 著; $13 \sim 14 \mathrm{~m}$ 高程区间的湿地植被分布面积与 10 月观测水位相关关系更强. 在南矶自然保护区, 湿地植被分布面积在不 同高程区间均与 9 和 10 月观测水位显著相关. 采用谐波分析方法分析湖泊湿地的植被分布面积与水位关系有助于基于 多时间序列遥感信息的湿地水文节律研究.
\end{abstract}

关键词: 鄱阳湖; 时间序列; 遥感数据; 谐波分析;水位;Pearson 相关分析

\section{Response on wetland vegetation distribution to hydrology regularity based on harmonic- time series analysis}

\author{
LIU Xuying ${ }^{1,2}$, GUAN Yanning ${ }^{1 * *}$, GUO Shan $^{1}$, ZHANG Chunyan $^{1} \&$ WANG Lei ${ }^{1,2}$ \\ (1: Institute of Remote Sensing and Digital Earth, Chinese Academy of Sciences, Beijing 100101, P.R. China) \\ (2: University of Chinese Academy of Sciences, Beijing 100049, P.R.China)
}

\begin{abstract}
This paper examines wetland vegetation distribution based upon perennial water levels and the time and spatial characteristics of wetland vegetation in various phonological phases. Harmonic components are extracted to describe wetland vegetation index and the changing patterns are used by remote sensing data in a high time resolution. This paper defines one analysis unit by a period from 2000 to 2013 as one hydrological year (from September to the next September). Changing patterns of wetland vegetation during different analysis units are expressed by the period of harmonic component which has the maximum amplitude. Results show: (1) Area of wetland vegetation in Lake Poyang Natural Reserve is significantly influenced by hydrological characteristics. Compared to that in Nanji Natural Reserve, wetland vegetation distribution in Lake Poyang Natural Reserve is more sensitive to the changes in water level. (2) Area of the wetland vegetation within natural reserves is negatively Pearson correlated with water level in a hydrological year (at a 0.05 significance level). Impact of recession date is larger than that of next-year flooding date on distribution of wetland vegetation, while water level in dry season is not significantly Pearson correlated with the distribution of two-growing-period wetland vegetation. (3) The Pearson correlations between distribution of wetland vegetation on different elevations and water level in the two natural reserves show distinct correlations. In Lake Poyang Natural Reserve, wetland vegetation distribution from the elevations $12-13 \mathrm{~m}$ has the strongest correlation with water level in September, and the wetland vegetation distribution
\end{abstract}

* 中国科学院信息化建设项目 (XXH12504-1-12) 资助.2015-03-13 收稿;2015-05-11 收修改稿.刘旭颖( 1989 ), 女, 硕士研究生; E-mail:liuxuying1213@163.com.

** 通信作者; E-mail:guanyn@ radi.ac.cn. 
from the elevations 13-14 m has the strongest correlation with water level in October. In Nanji Natural Reserve, the wetland vegetation distributions on different elevations are significantly correlated with water levels in September and October. A harmonic analysis is conducive to further study on wetland hydrology relations based on multi-temporal remote sensing data.

Keywords: Lake Poyang; long time series; remote sensing data; harmonic analysis; water level; Pearson correlation analysis

湿地水文过程作为影响湿地生态系统的重要因素之一, 不仅左右着湿地的物理、化学和生态过程, 也对 湿地发育演化和维持景观效益起到重要作用 ${ }^{[1]}$, 鄱阳湖水文过程同时受到贑、抚、信、饶、修五水及长江的影 响 ${ }^{[2]}$. 按照鄱阳湖水利枢纽建设办公室提供的观测数据, 自 1950 年以来, 鄱阳湖的水位 (星子水位) 在 7 $23 \mathrm{~m}$ 之间波动,最高水位为 $22.52 \mathrm{~m}$ (1998 年 8 月 2 日), 最低水位为 $7.11 \mathrm{~m}$ (2004 年 2 月 4 日).涉及鄱阳湖 湖泊水文节律的研究主要使用定位观测数据 ${ }^{[3-12]}$ 和遥感、 GIS $^{[12-14]}$ 等技术. 闵骞等自 $1990 \mathrm{~s}$ 开始, 持续关注鄱 阳湖观测水位数据, 从多角度描述鄱阳湖水位变化特征和规律, 并在此基础上讨论了围怎等人类活动对鄱 阳湖水位的影响 ${ }^{[9-11]}$. 李鹏等利用 1989-2010 年多期卫星影像信息提取湖泊面积,结合定位观测数据得到 了鄱阳湖水面面积随水位变化的关系 ${ }^{[12]}$. 针对鄱阳湖地区的湿地植被, 研究方法集中在采用传统的采样调 查 ${ }^{[15-21]}$ 、使用遥感数据反演生物量 ${ }^{[22]}$ 、解译植被种类 ${ }^{[19-22]}$ 等. 张全军等通过实地调查研究了南矶自然保护区 的植被类型及分布 ${ }^{[18]}$. 胡振鹏等利用 $3 \mathrm{~S}$ 技术对鄱阳湖湿地进行分类, 研究了主要植物群落结构和分布规 律 ${ }^{[19]}$. 葛刚等通过长期实地观测和调查描述了鄱阳湖地区优势植被种群的分布格局 ${ }^{[20]}$, 以及外来人侵种的 科目和对于鄱阳湖湿地的影响 ${ }^{[21]}$.

本文使用的谐波分析方法不仅在信号处理领域应用广泛, 随着遥感数据的积累, 也常见于对时间序列 遥感数据的处理. 谐波分析法能准确描述时间序列数据的变化规律, 在地表覆盖分析方面的应用已经比较成 熟 ${ }^{[25-34]}$. 于信芳等利用谐波分析的方法对我国东北森林物候期进行监测, 并获取了其空间分布格局 ${ }^{[33]}$. 本文 使用的遥感数据具有高时间分辨率的优点, 可以从多角度综合反映地表变化. 谐波分析的方法则可以将反映 地表变化的时间序列信号简化为不同的特征参量. 鄱阳湖因其湿地结构波动明显, 相对于瞬时数据, 谐波分 析结果能够更客观地反映鄱阳湖地表综合特征.

\section{1 研究区概况}

鄱阳湖位于江西省北部, 属于吞吐型湖泊.湖泊水面面积在夏季丰水期可达 $3700 \mathrm{~km}^{2}$ 以上, 在秋、冬枯水 期可缩小至不足 $1000 \mathrm{~km}^{2}$, 形成独特的 “丰水一片, 枯水一线” 的景观. 研究表明, 在吴淞高程 $12 \sim 16 \mathrm{~m}$ 的水 位升高过程中, 每升高 $1 \mathrm{~m}$, 主湖水面以超过 $300 \mathrm{~km}^{2}$ 的面积扩展. 其中 $12 \sim 13 \mathrm{~m}$ 为面积增加最大区间, 在 $12 \mathrm{~m}$ 升高到 $13 \mathrm{~m}$ 阶段, 水面扩展 $662.3 \mathrm{~km}^{2}$. 随着水位升高, 草洲、滩地的分布减少明显. 在 $12 \sim 14 \mathrm{~m}$ 区间, 草 洲随着水位每升高 $1 \mathrm{~m}$, 平均以超过 $300 \mathrm{~km}^{2}$ 的幅度减少 (1).这种随水位而导致湿地结构发生波动的变化规 律, 是自古鄱阳湖形成以来的典型特征 ${ }^{[2]}$. 研究样区选取鄱阳湖国家自然保护区 (以下简称鄱阳湖自然保护 区) 和南矶湿地国家级自然保护区 (以下简称南矶自然保护区) (图 1). 两个保护区为典型的水体一滩地一草 洲交错分布的湖泊湿地结构.

\section{2 数据处理}

\section{1 数据来源及预处理}

本文采用的数据主要有: MODIS-NDVI 16 日集成的标准产品数据(空间分辨率为 $250 \mathrm{~m}$ )、水文站定位观测 数据、DEM 数据. 标准产品数据的时间段为从 2000 年第 $49 \mathrm{~d}$ ( 2 月 18 日) 至 2013 年第 $353 \mathrm{~d}$ ( 12 月 19 日), 以 $16 \mathrm{~d}$ 为间隔,共计 319 期.MODIS-NDVI 数据产品由 MODIS 逐日数据计算, 经过 16 日最大值合成法 (MVC) 生 产. MVC ( Maximum Value Composite) 指的是用合成期内最大 NDVI 值代表这 16 日的地表 NDVI. 从 NASA 提供的 数据中提取出 NDVI 波段,通过遥感图像处理的标准化流程,并实现 WGS84/UTM50 坐标系的投影转换.

(1) 鄱阳湖水利枢纽工程对湿地与候鸟的影响及对策研究课题组, 李文华、刘兴士等. 鄱阳湖水利枢纽工程对湿地与 候鸟的影响及对策研究报告, 2010 年 10 月. 
DEM 数据(图 2) 是将 $1: 25000$ 比例尺等值 线 DEM 中的等高线离散化成为点数据, 并与 $1: 10000$ 比例尺等高点数据空间叠加后生成不 规则三角网 ( TIN), 在 TIN 的基础上内插值成规 则格网 DEM ${ }^{(1)}$.

\section{2 计算谐波分量特征值}

谐波分析指的是由 MODIS-NDVI 数据产 品得到每一个像元对应地表 NDVI 随时间变 化的离散波信号, 通过傅里叶变换将时间域 的波形变化到频率域, 用一系列正弦波来表 示 $N D V I$ 的波动 ${ }^{[23,28]}$. 不同的地表覆盖类型具 有不同的 $N D V I$ 变化模式, 差别在正弦波的中 心频率及振幅上. 假设 $f(x)$ 是 $[1, L]$ 上的连 续函数,则 $f(x)$ 在闭区间 $[1, L]$ 上的傅里叶 展开为: $f(x)=\sum_{n=1}^{\infty}\left(a_{n} \cos \frac{2 \pi n x}{L}+b_{n} \sin \right.$ $\left.\frac{2 \pi n x}{L}\right)+\frac{1}{2} a_{0}$, 式中, $L$ 为一个时间序列信号 的时间长度. 对于 $j \geqslant 1, f(x)$ 的第 $j$ 次傅里叶 展开为 $a_{j} \cos \frac{2 \pi n x}{L}+b_{j} \sin \frac{2 \pi n x}{L}$, 将第 $j$ 次展 开变换为单独余弦波来表示:

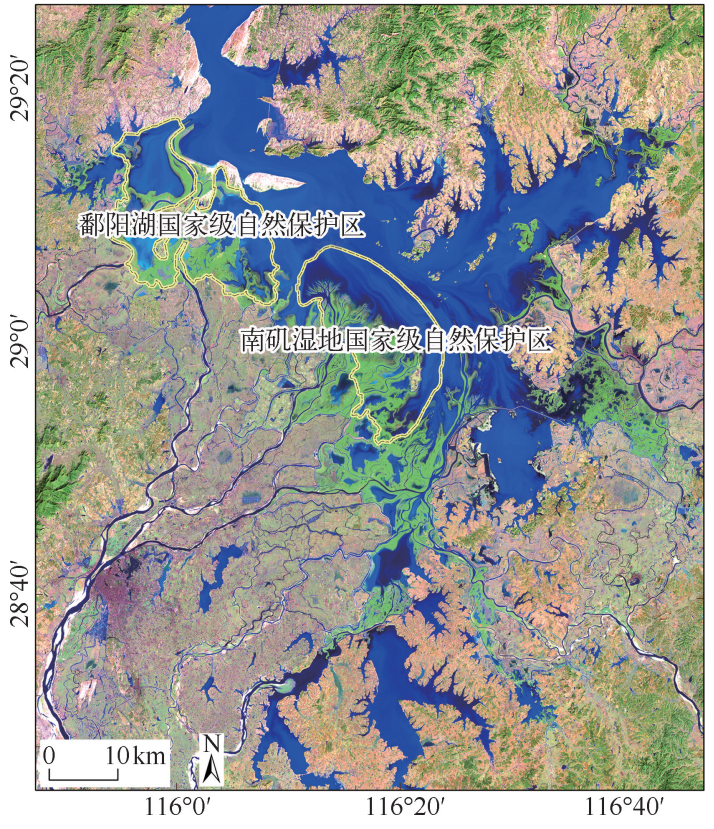

图 1 鄱阳湖内自然保护区区位 (底图为 1989 年 11 月 20 日 TM742 波段合成)

Fig. 1 National nature reserves inside Lake Poyang (Background is Landsat TM taken on Nov. 20th, 1989)

$$
\begin{aligned}
a_{j} \cos \frac{2 \pi n x}{L}+b_{j} \sin \frac{2 \pi n x}{L} & =\sqrt{a_{j}^{2}+b_{j}^{2}}\left(\frac{a_{j}}{\sqrt{a_{j}^{2}+b_{j}^{2}}} \cos \frac{2 \pi j x}{L}+\frac{b_{j}}{\sqrt{a_{j}^{2}+b_{j}^{2}}} \sin \frac{2 \pi j x}{L}\right) \\
& =\sqrt{a_{j}^{2}+b_{j}^{2}}\left(\cos \phi_{j} \cos \frac{2 \pi j x}{L}+\sin \phi_{j} \sin \frac{2 \pi j x}{L}\right) \\
& =c_{j} \cos \left(\frac{2 \pi j x}{L}-\phi_{j}\right)
\end{aligned}
$$

式中, $c_{j}=\sqrt{a_{j}^{2}+b_{j}^{2}}, \phi_{j}=\arctan \frac{b_{j}}{a_{j}}+\pi$, 令 $c_{0}=\frac{1}{2} a_{0}$, 则有 $f(x)=\sum_{n=1}^{\infty} c_{n}\left(\cos \frac{2 \pi n x}{L}-\phi_{j}\right)+c_{0}, c_{n}$ 表示第 $n$ 次展开的振幅, $\phi_{n}$ 表示第 $n$ 次展开的相位. 对于有限时间序列数据集, 应用离散傅里叶变换 (DFT) 得到离 散信号的分解展开式. 展开后, 关注每一个谐波分量的振幅和周期.振幅表示 $N D V I$ 时间序列相对于平均值的 波动, 谐波分量的振幅越大, 对应能量越高, 说明原始信号中这一谐波分量代表的变化模式越明显. 取振幅最 大的谐波分量,计算其对应的变化周期 $(T) . T$ 反映对应地表 $N D V I$ 在 $[1, L]$ 内的变化趋势和极值的个数.

\section{3 结果和分析}

\section{1 时间序列遥感数据谐波分析}

分别对全部 $14 \mathrm{a}$ 与每一水文年 (9月至次年 9 月) 两个不同尺度的遥感数据进行谐波分析,得到地表 $N D V I$ 主要变化谐波分量对应周期 $(T)$,如图 3、4、5.从图 3 可知 14 a 间鄱阳湖的湿地结构.根据谐波分析原 理和不同地表类型在红光波段及近红外波段反射特点,将无明显周期性变化特征的像元判定为水体. $T=1 \mathrm{a}$

(1) 鄱阳湖水利枢纽工程对湿地与候鸟的影响及对策研究课题组, 李文华、刘兴士等. 鄱阳湖水利枢纽工程对湿地与 候鸟的影响及对策研究报告, 2010 年 10 月. 
的区域为水体、含植被水体、滩地、水一滩过渡带等; $T=0.5 \mathrm{a}$ 的区域是鄱阳湖的草洲带. 鄱阳湖湿地主要的植 被群落种类有芦苇群落、南荻群落、苔草群落等, 这些群落存在不同程度的镶嵌情况,一般呈现出春季及秋 季两次生长周期 ${ }^{[18]}$, 即 $T=0.5$ a. 因此选择 $N D V I$ 变化周期为半年的区域特征值表征湿地植被群落分布. 湿地 植被群落多分布于子湖周边以及人湖河流的各级支流周边. 不同的地表覆盖具有不同的高程分布特征, 水一 滩过渡带主要在 $11 \sim 12 \mathrm{~m}$, 草洲带主要分布在 $12 \mathrm{~m}$ 以上的高程范围.

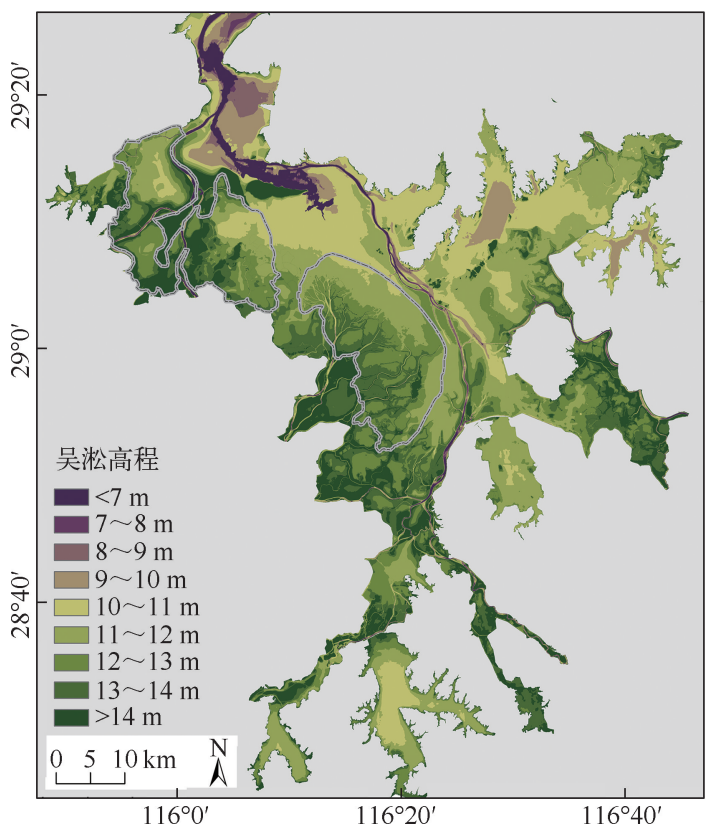

图 2 鄱阳湖 $\mathrm{DEM}$ (吴淞高程)

Fig. 2 DEM of Lake Poyang

( The same reference datum as water level)

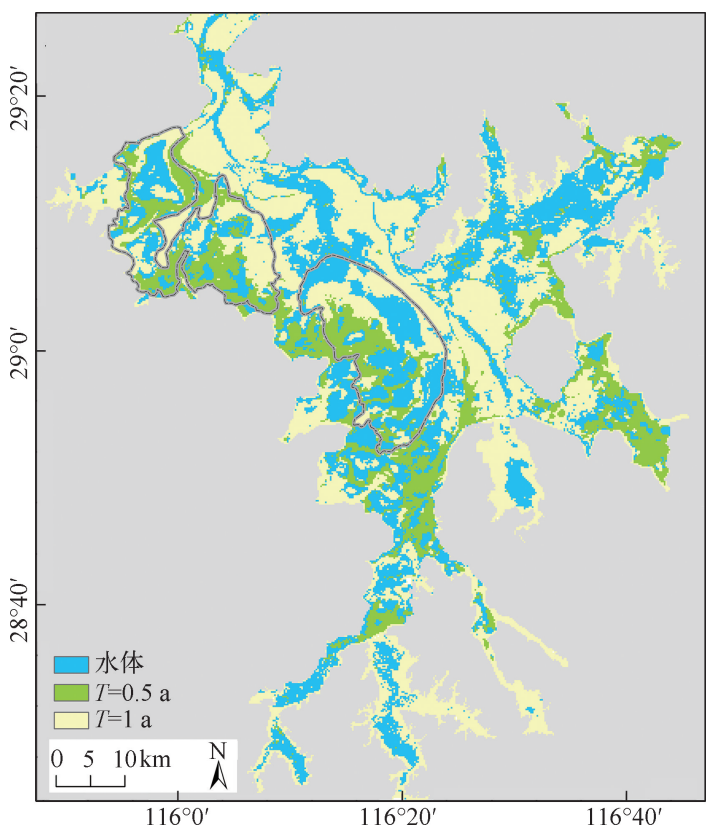

图 $32000-2013$ 年鄱阳湖地区 $N D V I$ 时间序列谐波分析图

Fig.3 Harmonic analysis result of time series NDVI dataset of Lake Poyang during 2000-2013

图 4 、图 5 分别为两个保护区 $N D V I$ 在每一水文年内的变化模式,例如 $T=3 \sim 4$ 月. 在鄱阳湖自然保护区, 湿地植被分布主要集中在蛙湖东侧带状区域、大湖池周边以及保护区东南众多小型子湖周边. 当湿地植被分 布减少时, 大湖池周边的分布首先减少; 当湿地植被分布增加时,其分布向主湖区蔓延. 在南矶自然保护区, 湿地植被在高程 $12 \mathrm{~m}$ 分布广泛,多集中于各子湖周边.

根据每一水文年和 $14 \mathrm{a}$ 的谐波分析结果中 $T=0.5 \mathrm{a}$ 所占比例 (表 1 、图 6), 在两个保护区中, 鄱阳湖自 然保护区内湿地植被分布随着水位波动更大. 以 $14 \mathrm{a}$ 结果以 $\pm 15 \%$ 为分析阈值, 即鄱阳湖自然保护区结果阈 值区间为 $[21.21 \%, 51.21 \%]$, 南矶自然保护区结果阈值区间为 [ $8.68 \%, 38.68 \%$ ]. 在阈值范围外的年份有 2000－2001、2005－2006、2006-2007、2010－2011、2012-2013 水文年,其余年份与 14 a 结果相近.

根据鄱阳湖国家自然保护区管理局提供的 2009 年 10 月蚌湖实地调查结果 (图 7、表 2)、张全军、 胡振鹏、葛刚等学者关于鄱阳湖地区主要湿地植被种类物候期的描述 ${ }^{[18-20]}$ (图 8 ) 以及各点高程得出在 2009-2010 水文年各点 $N D V I$ 的变化模式. A、B、C、D 点主要植被覆盖类型为苔草科和芦苇, 高程均大 于 $13 \mathrm{~m}$. 根据 2009-2010 水文年水位数据, A D 点所呈现的 $N D V I$ 变化模式主要由湿地植被的物候 期决定, 因此谐波分析结果为 $T=0.5$ a. 而 $\mathrm{E} 、 \mathrm{~F} 、 \mathrm{G}$ 点的高程小于 $13 \mathrm{~m}$, 根据水位数据, 在 $2009-2010$ 水文年内, 仅在其秋季生长期有长时间的露出, 因此, 对应的 $N D V I$ 变化模式是以 $1 \mathrm{a}$ 为周期的, 与谐波 分析得到的结果一致. 

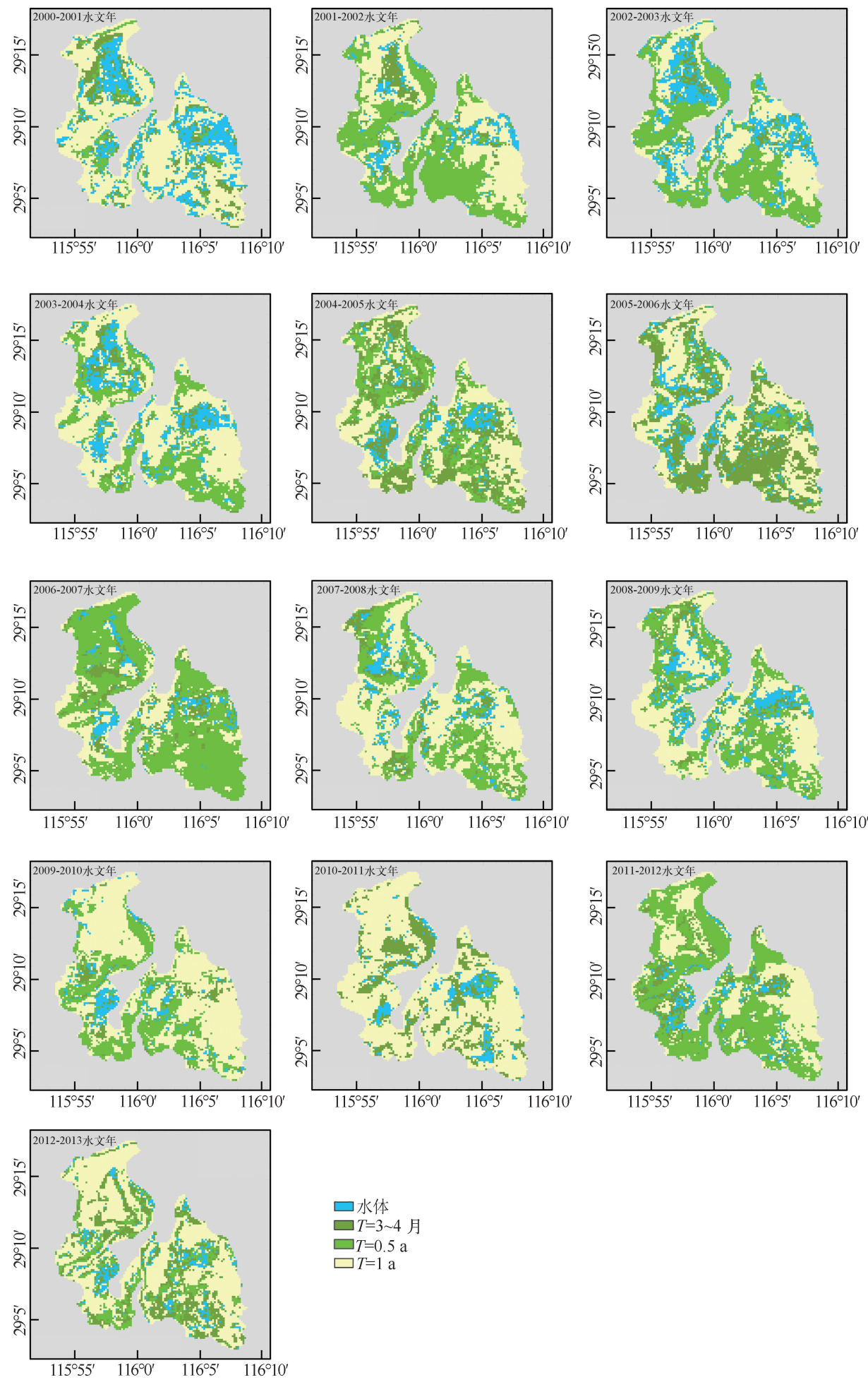

图 4 鄱阳湖自然保护区各年 NDVI 时间序列谐波分析

Fig.4 Harmonic analysis result of Lake Poyang Natural Reserve of time series

$N D V I$ dataset in every hydrological year 

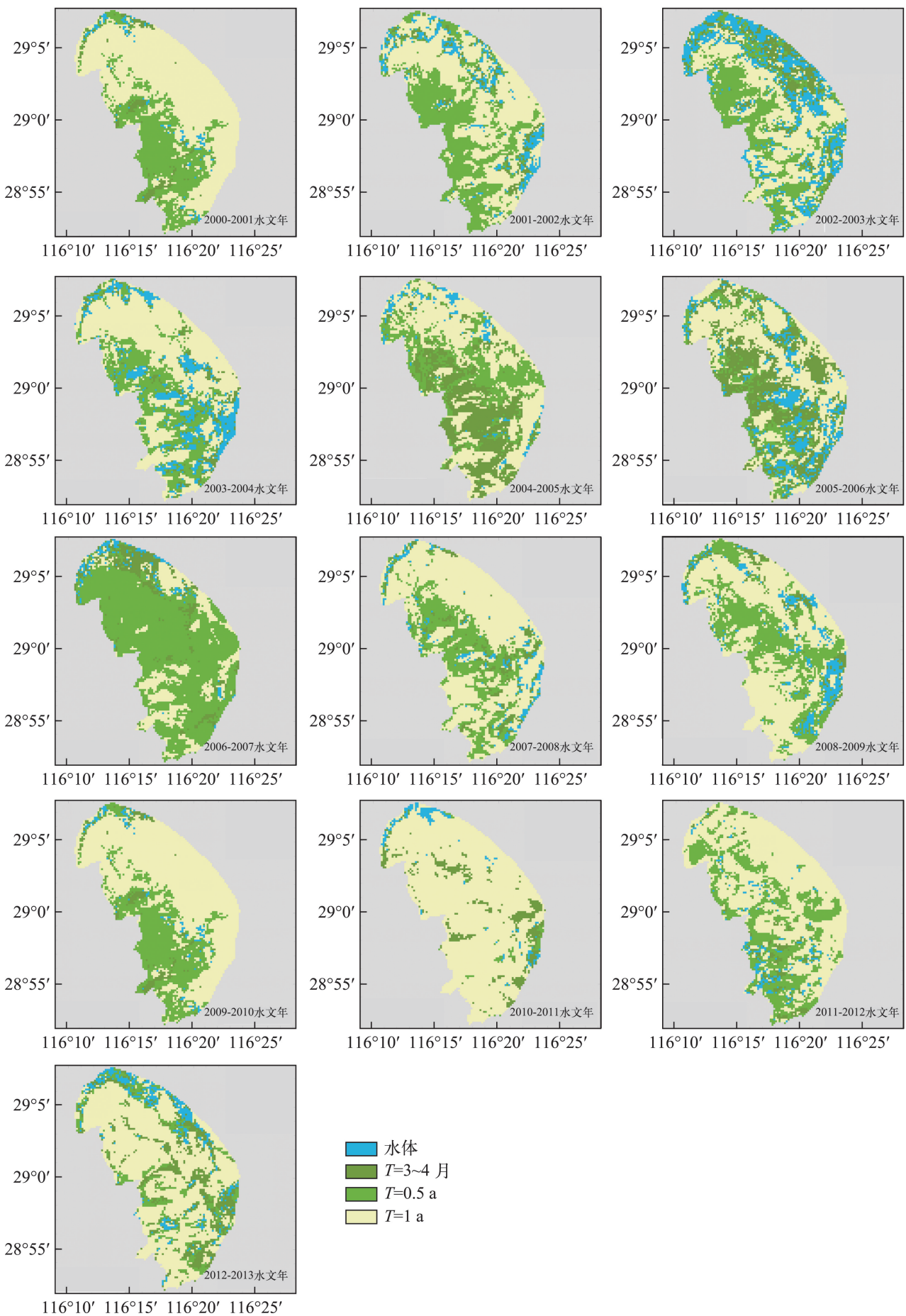

图 5 南矶自然保护区各年 $N D V I$ 时间序列谐波分析

Fig.5 Harmonic analysis results of Nanji Natural Reserve of time series NDVI dataset in every hydrologic year 
表 1 谐波分析中 $T=0.5 \mathrm{a}$ 结果占保护区面积的比例(\%)

Tab.1 Percentage of “ $T=0.5$ a” in every harmonic result

\begin{tabular}{|c|c|c|c|c|c|c|c|c|c|c|c|c|c|c|}
\hline & 2000 & 2001 & 2002 & 2003 & 2004 & 2005 & 2006 & 2007 & 2008 & 2009 & 2010 & 2011 & 2012 & $14 \mathrm{a}$ \\
\hline & - & - & - & - & - & - & - & - & - & - & - & - & - & 综合 \\
\hline & 2001年 & 2002年 & 2003年 & 2004年 & 2005年 & 2006年 & 2007年 & 2008年 & 2009年 & 2010年 & 2011年 & 2012年 & 2013年 & 结果 \\
\hline $\begin{array}{l}\text { 鄱阳湖自 } \\
\text { 然保护区 }\end{array}$ & 7.30 & 42.90 & 38.50 & 26.52 & 23.66 & 9.74 & 59.68 & 31.31 & 32.44 & 28.14 & 1.68 & 49.65 & 13.54 & 36.21 \\
\hline $\begin{array}{l}\text { 南矶自然 } \\
\text { 保护区 }\end{array}$ & 7.83 & 32.98 & 27.42 & 23.72 & 22.12 & 12.43 & 65.00 & 24.27 & 29.58 & 27.16 & 1.44 & 28.27 & 10.81 & 23.68 \\
\hline
\end{tabular}

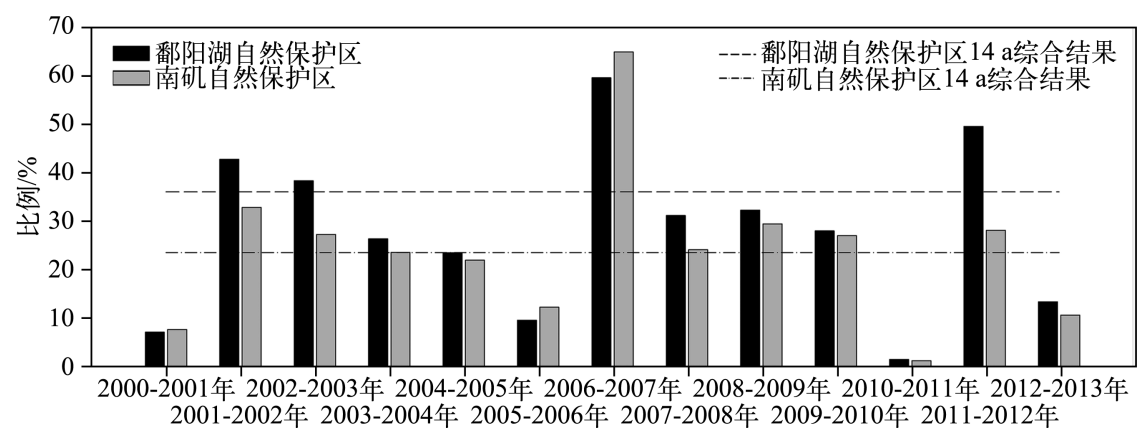

图 6 谐波分析中 $T=0.5 \mathrm{a}$ 所占比例

Fig.6 Percentage of “ $T=0.5$ a” in every harmonic result

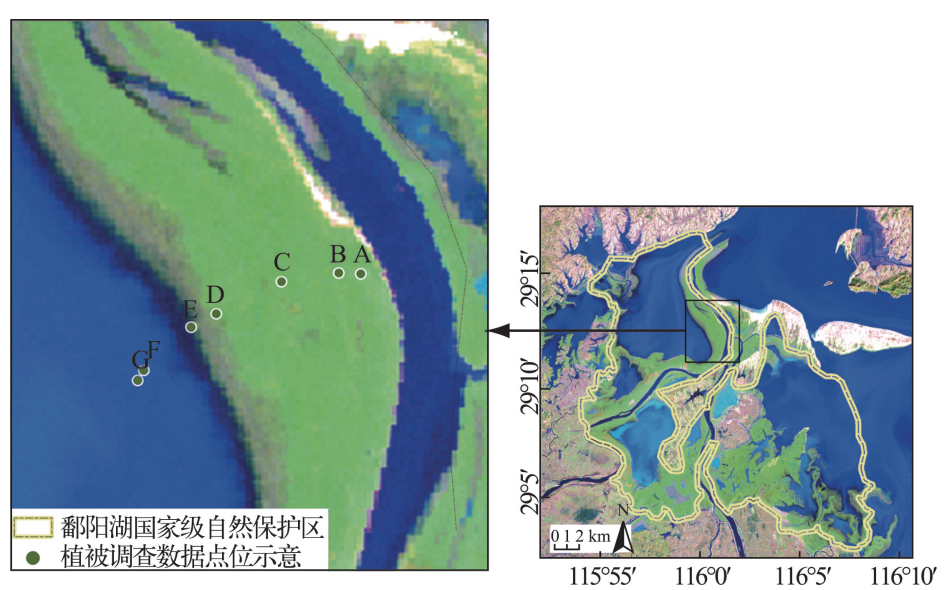

图 7 实地调查样点位置

Fig.7 Field vegetation survey spots

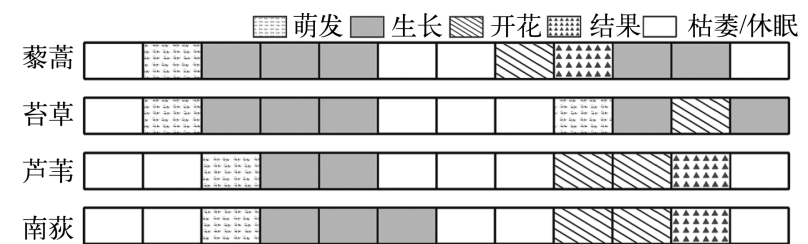

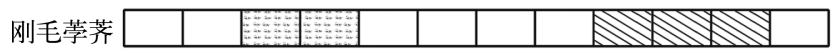

1月，2月，3月，4月，5月，6月，7月，8月，9月，10月，11月，12月

图 8 湿地植被物候期 ${ }^{[18-19]}$

Fig.8 Phenology of wetland vegetation ${ }^{[18-19]}$ 
表 2 实地调查采样结果

Tab. 2 Field vegetation result

\begin{tabular}{|c|c|c|c|c|c|c|c|c|c|c|}
\hline \multirow[b]{2}{*}{ 采样点 } & \multicolumn{8}{|c|}{ 盖度 $\% \%$} & \multirow{2}{*}{$\begin{array}{l}\text { 谐波分 } \\
\text { 析结果 }\end{array}$} & \multirow{2}{*}{$\begin{array}{c}\text { DEM } \\
\text { (吴淞高程: } \mathrm{m} \text { ) }\end{array}$} \\
\hline & 芦苇 & 南荻 & 糠稷 & $\begin{array}{l}\text { 灰化 } \\
\text { 苔草 }\end{array}$ & $\begin{array}{l}\text { 䊁叶 } \\
\text { 苔草 }\end{array}$ & $\begin{array}{l}\text { 刚毛 } \\
\text { 蒙荠 }\end{array}$ & 水蓼 & $\begin{array}{l}\text { 水田碎 } \\
\text { 米荠 }\end{array}$ & & \\
\hline A & - & 10.0 & 18.3 & 78.3 & - & - & - & - & $T=0.5 \mathrm{a}$ & 15.0 \\
\hline B & 8.3 & 13.3 & - & 83.3 & - & - & - & - & $T=0.5 \mathrm{a}$ & 14.6 \\
\hline C & 70.0 & - & - & - & 16.7 & - & 7.0 & - & $T=0.5 \mathrm{a}$ & 14.0 \\
\hline D & - & 28.3 & - & - & 81.7 & - & - & - & $T=0.5 \mathrm{a}$ & 13.2 \\
\hline $\mathrm{E}$ & - & - & - & - & 94.3 & - & - & - & $T=1 \mathrm{a}$ & 12.6 \\
\hline $\mathrm{F}$ & - & - & - & 36.7 & - & 13.3 & 10.3 & 50.0 & $T=1 \mathrm{a}$ & 11.6 \\
\hline G & - & - & - & - & 16.7 & 50.0 & 11.7 & 56.7 & $T=1 \mathrm{a}$ & 11.5 \\
\hline
\end{tabular}

\section{2 水位变化规律}

鄱阳湖主要水文站有都昌站、棠阴站、星子站和吴城站等, 其中吴城站水位取吴城赣江站和吴城修水站 水位数据平均值. 将都昌水位与其他水文站水位进行拟合, 均呈现较好的拟合效果 (图 9), 故选择都昌站水 位数据进行分析.按 3.1 节中分析结果将这 $14 \mathrm{a}$ 数据分成两组分别观察水位变化规律(图 10 ).
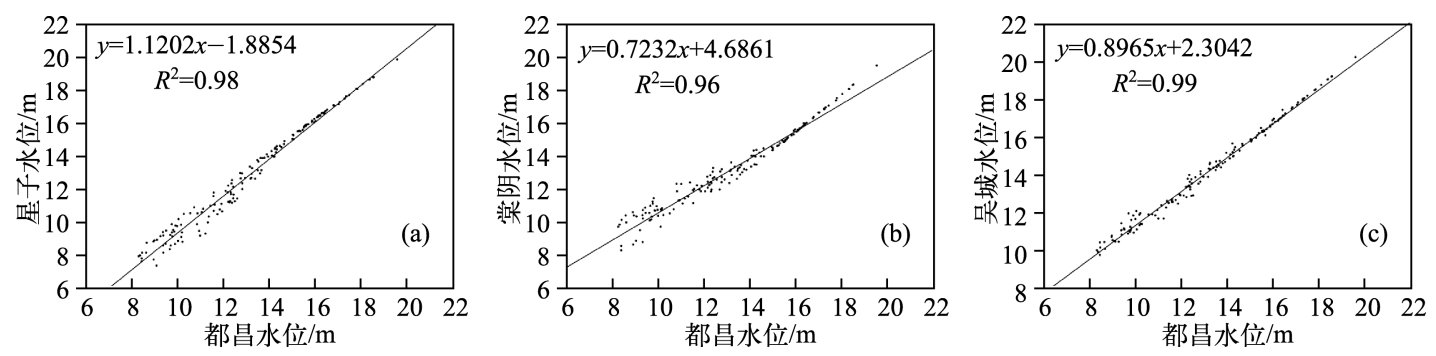

图 9 都昌水位与星子、棠阴、吴城水位的拟合关系

Fig.9 Relationships between water level of Duchang and Xingzi, Tangyin, Wucheng
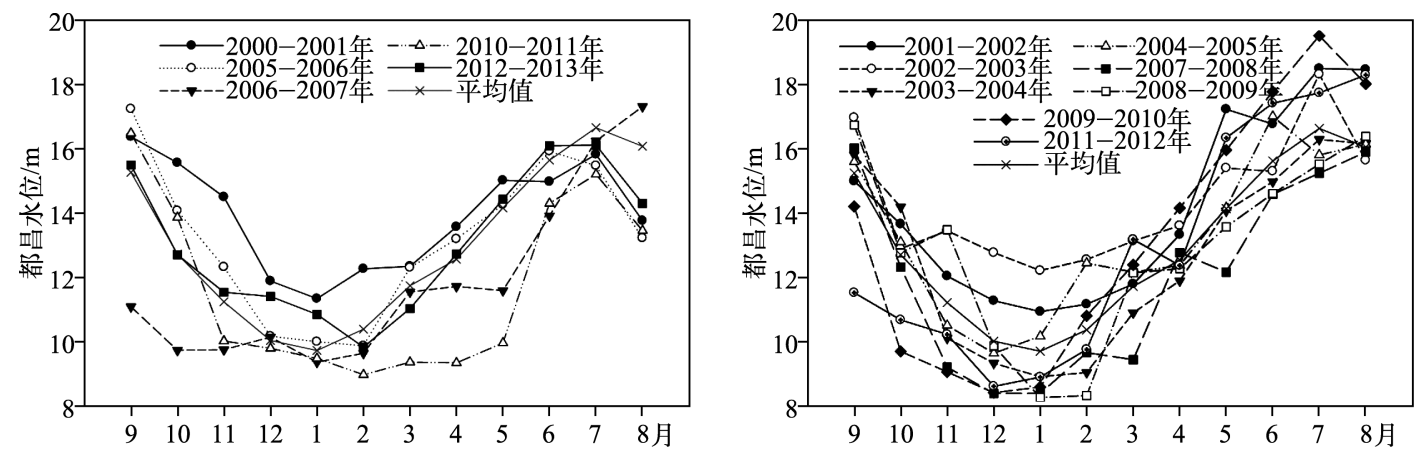

图 10 不同水文年月均都昌水位变化

Fig.10 Average water level per month during selected hydrological years

在谐波分析结果异常的水文年中 9、10 月和次年 4、5 月都昌水位相对于 $14 \mathrm{a}$ 平均水位出现明显偏移.例 如在分布比例超过 60\% 以上的 2006-2007 水文年, 9-10 月呈现低水位、小幅度减少趋势; 在次年 4-5 月 呈现低水位、小幅度增加趋势.而其他年份的水位偏移主要集中于 11 月至次年 2 月.

在 2000-2001 水文年的秋季生长期,即 10 月及 11 月, 都昌水位比平均水位高出 $3 \mathrm{~m}$ 左右.而 2005- 
2006 水文年, 水位波动与 $14 \mathrm{a}$ 平均水位波动模式相似.但根据都昌每日水位数据, 在该水文年丰转枯和枯转 丰这两个变化过程中的高程 10 13 $\mathrm{m}$ 区间, 出现多个极值水位, 造成水与滩之间湿地结构的反复变化, 使得 这些区域湿地植被的 $N D V I$ 变化模式变成了以 3 4 个月为周期. 在 2010-2011 水文年, 10 月至次年 5 月的 平均水位均在 9 10 m. 比较草洲带这一水文年与其他年份同一地表区域对应象元的 $\mathrm{Z}$ 谱曲线, 在这一水文 年的 12 月至次年 2 月, 即主要湿地植被的枯萎期, $N D V I$ 没有变小, 因此导致谐波分析结果出现绝大区域均 为 $T=1 \mathrm{a}$ 的情况. 类似的规律也曾出现在 2012-2013 水文年.

与之形成对比的是 2006-2007 水文年的分析结果. 水位波动虽与 2010-2011 水文年相似,枯水位较 低,但谐波分析结果与 2010-2011 水文年恰好相反, 湿地植被分布高达 60\% 以上.2006-2007 水文年秋季 生长期水位较低, 不仅为高程在 $13 \mathrm{~m}$ 以上的草洲带提供了湿地植被生长的必需条件, 同时为更低高程区域 的植被提供了足够的生长时间. 该水文年的春季 $2-3$ 月水位开始出现明显上涨, 为湿地植被的春季生长提 供了充足的水环境. 因此在两个保护区内, 一年两次生长期的湿地植被群落分布广泛. 出现类似结果的还有 2011-2012 水文年. 该水文年的 9 月及 10 月水位与 $14 \mathrm{a}$ 平均水位相差 $3 \mathrm{~m}$ 以上,其湿地植被分布比例明显 大于总 $14 \mathrm{a}$ 的结果, 尤其在鄱阳湖自然保护区.

\section{3 湿地植被分布面积与水位的相关性分析}

根据各水文站的地理位置, 分别选择吴城站和棠阴站观测水位分析鄱阳湖自然保护区湿地植被分布面 积与水位变化之间的关系 (表 3 ).

表 3 湿地植被分布与各月水位的相关系数 $(P)$ 和显著性系数 ( Sig.)

Tab.3 Pearson correlation and significance between distribution of wetland vegetation area and water levels per month

\begin{tabular}{|c|c|c|c|c|c|c|c|c|c|c|c|c|c|c|c|c|}
\hline & \multicolumn{2}{|c|}{9 月 } & \multicolumn{2}{|c|}{10 月 } & \multicolumn{2}{|c|}{11 月 } & \multicolumn{2}{|c|}{12 月 } & \multicolumn{2}{|c|}{ 次年 1 月 } & \multicolumn{2}{|c|}{ 次年 2 月 } & \multicolumn{2}{|c|}{ 次年 3 月 } & \multicolumn{2}{|c|}{ 次年 4 月 } \\
\hline & $P$ & Sig. & $P$ & Sig. & $P$ & Sig. & $P$ & Sig. & $P$ & Sig. & $P$ & Sig. & $P$ & Sig. & $P$ & Sig. \\
\hline $\begin{array}{l}\text { 鄱阳湖自 } \\
\text { 然保护区 } \\
\text { 湿地植被 } \\
\text { 面积一吴 } \\
\text { 城水位 }\end{array}$ & -0.71 & 0.01 ** & -0.66 & $0.01^{* *}$ & -0.24 & 0.44 & -0.20 & 0.51 & -0.20 & 0.54 & -0.11 & 0.73 & 0.26 & 0.42 & 0.13 & 0.68 \\
\hline $\begin{array}{l}\text { 南矶自然 } \\
\text { 保护区湿 } \\
\text { 地植被面 } \\
\text { 积一棠阴 } \\
\text { 水位 }\end{array}$ & -0.66 & $0.02^{*}$ & -0.62 & $0.02^{*}$ & -0.23 & 0.46 & -0.16 & 0.61 & -0.20 & 0.51 & -0.11 & 0.73 & 0.17 & 0.58 & 0.16 & 0.59 \\
\hline
\end{tabular}

*** 表示在 0.01 水平上显著; *表示在 0.05 水平上显著,下同.

相关分析结果表明, 在鄱阳湖自然保护区和南矶自然保护区, 湿地植被的分布与对应水文年 9 月的水 位有紧密的负相关性, 与 10 月水位相关性稍差, 均呈显著相关, 与其他月份的水位相关性较小. 在 20062007 以及 $2011-2012$ 水文年, 9 月及 10 月的水位比 $14 \mathrm{a}$ 平均水位低 $2 \mathrm{~m}$ 以上, 因此对应水文年的湿地植被 分布比例高.在 2000-2001、2005-2006 水文年,9、10 月吴城和棠阴水位均明显大于 14 a 平均值,因此对应 水文年的湿地植被分布比例低. 鄱阳湖自然保护区湿地植被分布与水位的相关系数大于南矶自然保护区, 说 明鄱阳湖自然保护区的湿地植被分布面积对于水位变化更加敏感. 结合鄱阳湖地区的水文特征, 9 月及 10 月的水位反映了对应水文年的退水时间,次年 $3 、 4$ 月水位则反映了鄱阳湖地区次年涨水时间 ${ }^{[2]}$. 因此退水时 间对湿地植被影响较大.

\section{4 不同高程湿地植被分布面积对水位变化的响应}

结合 DEM 数据(图 2), 在大于 $12 \mathrm{~m}$ (吴淞高程) 的区域, 以 $1 \mathrm{~m}$ 为间隔统计湿地植被占保护区面积的比 例结果 (图 11) 表明, 在鄱阳湖自然保护区, 湿地植被在 $12 \mathrm{~m}$ 以上的高程区间均有分布, 且各高程分布相对 南矶自然保护区比较均匀.而在南矶自然保护区, 湿地植被主要集中于 $12 \sim 14 \mathrm{~m}$ 的高程区间, 在大于 $14 \mathrm{~m}$ 高 程上分布较少. 

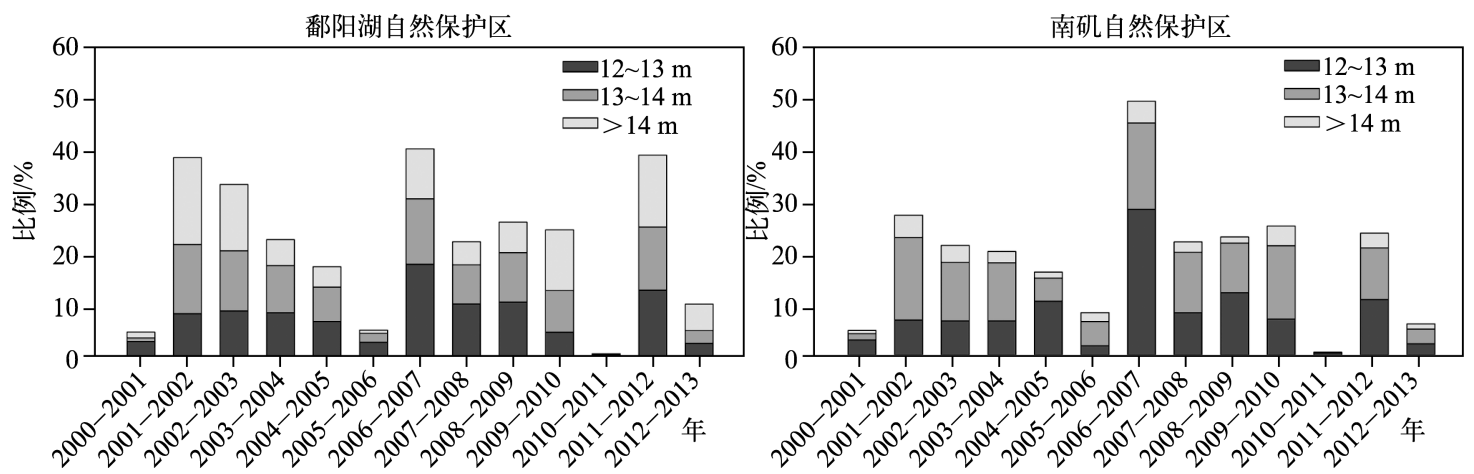

图 11 鄱阳湖自然保护区和南矶自然保护区湿地植被在不同高程的分布比例

Fig.11 Percentage of distribution of wetland vegetaton on different heights in Lake Poyang

Natural Reserve and Nanji Natural Reserve

分别计算不同高程鄱阳湖自然保护区湿地植被面积与吴城水位的相关关系和显著性系数 (表 4), 南矶 自然保护区湿地植被面积与棠阴水位的相关关系和显著性 (表 5). 在不同高程, 湿地植被的分布与水位的相 关关系不同.

1) 12 13 m: 湿地植被分布面积主要受 $9 、 10$ 月水位影响,且均显著相关;

2) 13 14 m: 鄱阳湖自然保护区的湿地植被分布面积同时与 9、10 月水位呈负相关, 相关程度相近; 南 矶自然保护区的湿地植被主要受 10 月棠阴水位影响,与次年 4 月水位呈弱相关;

3) $>14 \mathrm{~m}$ : 湿地植被分布同时受到 $9 、 10$ 月和次年 4 月水位影响.湿地植被的分布与 $9 、 10$ 月都昌水位的 相关关系在不同水平上 $(0.05 \sim 0.10)$ 显著, 但与次年 4 月水位关系不显著. 相对于鄱阳湖自然保护区, 南矶自 然保护区的湿地植被分布与水位相关关系更显著.

表 4 鄱阳湖自然保护区不同高程湿地植被分布与吴城水位的相关系数和显著性系数

Tab.4 Correlation and significance between distribution of wetland vegetation in Lake Poyang Natural Reserve on different height and water level of Wucheng per month

\begin{tabular}{|c|c|c|c|c|c|c|c|c|c|c|c|c|c|c|c|c|}
\hline \multirow{2}{*}{ 高程 } & \multicolumn{2}{|c|}{9 月 } & \multicolumn{2}{|c|}{10 月 } & \multicolumn{2}{|c|}{11 月 } & \multicolumn{2}{|c|}{12 月 } & \multicolumn{2}{|c|}{ 次年 1 月 } & \multicolumn{2}{|c|}{ 次年 2 月 } & \multicolumn{2}{|c|}{ 次年 3 月 } & \multicolumn{2}{|c|}{ 次年 4 月 } \\
\hline & $P$ & Sig. & $P$ & Sig. & $P$ & Sig. & $P$ & Sig. & $P$ & Sig. & $P$ & Sig. & $P$ & Sig. & $P$ & Sig. \\
\hline $12 \sim 13 \mathrm{~m}$ & -0.65 & $0.02 * *$ & -0.57 & $0.04^{* * *}$ & -0.22 & 0.48 & -0.27 & 0.37 & -0.30 & 0.34 & -0.25 & 0.44 & 0.14 & 0.66 & -0.05 & 0.87 \\
\hline $13 \sim 14 \mathrm{~m}$ & -0.54 & $0.06^{*}$ & -0.54 & $0.06^{*}$ & -0.16 & 0.60 & -0.13 & 0.67 & -0.16 & 0.62 & 0.10 & 0.76 & 0.25 & 0.43 & 0.19 & 0.55 \\
\hline$>14 \mathrm{~m}$ & -0.54 & $0.06^{*}$ & -0.55 & $0.05^{*}$ & -0.12 & 0.71 & -0.01 & 0.97 & 0.03 & 0.93 & 0.13 & 0.68 & 0.39 & 0.21 & 0.41 & 0.19 \\
\hline
\end{tabular}

表 5 南矶自然保护区不同高程湿地植被分布与棠阴水位的相关系数和显著性系数

Tab.5 Correlation and significance between distribution of wetland vegetation in Nanji Natural Reserve on different heights and water level of Tangyin per month

\begin{tabular}{|c|c|c|c|c|c|c|c|c|c|c|c|c|c|c|c|c|}
\hline \multirow{2}{*}{ 高程 } & \multicolumn{2}{|c|}{9 月 } & \multicolumn{2}{|c|}{10 月 } & \multicolumn{2}{|c|}{11 月 } & \multicolumn{2}{|c|}{12 月 } & \multicolumn{2}{|c|}{ 次年 1 月 } & \multicolumn{2}{|c|}{ 次年 2 月 } & \multicolumn{2}{|c|}{ 次年 3 月 } & \multicolumn{2}{|c|}{ 次年 4 月 } \\
\hline & $P$ & Sig. & $P$ & Sig. & $P$ & Sig. & $P$ & Sig. & $P$ & Sig. & $P$ & Sig. & $P$ & Sig. & $P$ & Sig. \\
\hline $12 \sim 13 \mathrm{~m}$ & -0.63 & 0.01 ** & -0.60 & $0.03^{\text {*** }}$ & -0.25 & 0.42 & -0.21 & 0.50 & -0.26 & 0.40 & -0.13 & 0.67 & 0.12 & 0.71 & -0.02 & 0.95 \\
\hline $13 \sim 14 \mathrm{~m}$ & -0.51 & $0.08^{*}$ & -0.57 & $0.04^{\text {*** }}$ & -0.29 & 0.34 & -0.28 & 0.35 & -0.30 & 0.32 & -0.11 & 0.72 & 0.16 & 0.61 & 0.39 & 0.19 \\
\hline$>14 \mathrm{~m}$ & -0.57 & $0.04^{* *}$ & -0.56 & $0.05^{*}$ & -0.21 & 0.49 & -0.04 & 0.91 & 0.02 & 0.95 & 0.12 & 0.70 & 0.31 & 0.31 & 0.45 & 0.12 \\
\hline
\end{tabular}

\section{4 结语}

本文采用时间序列遥感数据的谐波分析, 根据鄱阳湖地区主要湿地植被种类的物候特征, 以 NDVI 变化 
周期为半年的区域特征值表征湿地植被群落分布. 结合鄱阳湖的 DEM 数据与吴城站、棠阴水位数据, 分析了 湿地植被对水位变化的特征与规律,得出以下结论:

1) 两个保护区中,鄱阳湖国家级自然保护区湿地植被群落分布对水位的变化更为敏感.鄱阳湖自然保 护区的湿地植被分布面积与 $9 、 10$ 月吴城水位相关系数分别为 -0.71 和 -0.66 , 均大于南矶自然保护区与棠 阴水位的 -0.66 和 -0.62 .

2) 两个保护区范围内的湿地植被分布与对应水文年 $9 、 10$ 月的水位呈现比较强的负相关性, 且在 0.05 水平上显著.

3) 不同高程的湿地植被群落分布与水位关系不同. 在吴淞高程 12 13 $\mathrm{m}$ 的湿地植被群落分布与 9 月水 位相关性最强, 且显著相关; 在 13 14 $\mathrm{m}$ 高程的湿地植被分布与 10 月水位相关关系的显著性强于 9 月水位. 南矶自然保护区在各高程的湿地植被分布与水位相关关系的显著性强于鄱阳湖自然保护区.

4) 鄱阳湖地区呈现一年两季生长的湿地植被受退水时间影响最大, 其次是次年的涨水时间, 与枯水期 水位无明显的相关关系.

本文所用方法可以得到对于每一年地表变化的综合评价, 避免了瞬时观测数据的偶然性误差, 为不同 年份之间进行动态对比提供了标准化的指标. 采用谐波分析得到湿地植被的分布与水位关系结果, 与叶春等 使用生物量作为指标获取的结果 ${ }^{[35-36]}$ 变化趋势一致.

将 $T=0.5 \mathrm{a}$ 作为鄱阳湖主要湿地植被的表征,并不代表其他区域没有湿地植被分布, 只是在 $250 \mathrm{~m}$ 空间 分辨率的尺度上没有显现.

由于本文采用的 MODIS-NDVI 数据产品起始于 2000 年, 采用谐波分析研究湿地植被与水位变化, 需要 在进一步研究中补充更长时间序列的高时间分辨率遥感数据.

鄱阳湖水利枢纽建设办公室提供的资料显示, 鄱阳湖受人为扰动因素影响, 湖区的 61 个碟形子湖中, 有 44 个设有水闸进行水位控制, 仅有 17 个子湖处于与鄱阳湖自然连通的状态. 在人工调控背景下, 对于水 文节律改变的影响以及湿地植被对水文节律的响应关系等变化, 需要在日后长期的研究中加以深化.

致谢: 鄱阳湖水利枢纽工程建设办公室提供水位观测数据, 鄱阳湖国家级自然保护区管理局提供实地采样 数据和吴城赣江、修水水位观测数据, 在此一并表示感谢.

\section{5 参考文献}

[ 1 ] 邓 伟, 胡金明. 湿地水文学研究进展及科学前沿问题. 湿地科学, 2003, 1(1): 12-20.

[ 2 ] 朱海虹. 鄱阳湖: 水文. 生物 - 沉积・湿地 - 开发整治. 合肥: 中国科学技术大学出版社, 1997: 170.

[ 3 ] 刘成林, 谭胤静, 林联盛等. 鄱阳湖水位变化对候鸟栖息地的影响. 湖泊科学, 2011, 23(1): 129-135. DOI 10. 18307/2011. 0119.

[ 4 ] 蔡晓斌, 陈晓玲, 王学雷等. 鄱阳湖水位空间差异及其对湿地水文分析的影响. 华中师范大学学报: 自然科学版, 2011, 45(1) : 139-144.

[ 5 ] 郭 华, 苏布达, 王艳君等. 鄱阳湖流域 1955-2002 年径流系数变化趋势及其与气候因子的关系. 湖泊科学, 2007, 19(2) : 163-169. DOI 10. 18307/2007. 0209.

[ 6 ] Guo H, Hu Q, Jiang T. Annual and seasonal streamflow responses to climate and land-cover changes in the Poyang Lake basin, China. Journal of Hydrology, 2008, 355(1) : 106-122.

[ 7 ] Jiang JH, Huang Q. 三峡工程对鄱阳湖水位影响研究. 自然资源学报, 1997, 12(3) : 219-224.

[ 8 ] Shankman D, Keim BD, Song J. Flood frequency in China's Poyang Lake region: trends and teleconnections. International Journal of Climatology, 2006, 26(9): 1255-1266.

[ 9 ] 闵 寒. 20 世纪 90 年代鄱阳湖洪水特征的分析. 湖泊科学, 2002, 14(4) : 323-330. DOI 10. 18307/2002. 0405 .

[10]闵 寒. 近 50 年鄱阳湖形态和水情的变化及其与围旺的关系. 水科学进展, 2000, 11(1): 76-81.

[11] 闵 骞, 刘 影, 马定国. 退田还湖对鄱阳湖洪水调控能力的影响. 长江流域资源与环境, 2006, 15(5): 574-578.

[12] 李 鹏, 封志明, 姜鲁光等. 鄱阳湖天然湖面遥感监测及其与水位关系研究. 自然资源学报, 2013, 28 (9): $1556-1568$.

[13] 龚 伟, 杨大文, 钱 群. 基于 MODIS 数据的洞庭湖水面面积估算方法. 人民长江, 2009, 40(14): 40-43.

[14] 顾中宇. 鄱阳湖水文特征分析及水体形态特征的遥感提取 [ 学位论文]. 南昌: 江西师范大学, 2007. 
[15] 吴建东, 刘观华, 金杰峰等. 鄱阳湖秋季洲滩植物种类结构分析. 江西科学, 2010, 28(4) : 549-554.

[16] 张丽丽, 殷峻暹, 蒋云钟等. 鄱阳湖自然保护区湿地植被群落与水文情势关系. 水科学进展, 2012, 23(6): 768-775.

[17] 赵安娜. 鄱阳湖湿地植物一土壤一微生物多样性对水文过程变化的响应 [学位论文]. 南昌: 南昌大学, 2012.

[18］张全军, 于秀波, 胡斌华. 鄱阳湖南矶湿地植物群落分布特征研究. 资源科学, 2013, 35(1): 42.

[19] 胡振鹏, 葛 刚, 刘成林等. 鄱阳湖湿地植物生态系统结构及湖水位对其影响研究. 长江流域资源与环境, 2010, 19(6) : 597-605.

[20］葛 刚, 赵安娜, 钟义勇等. 鄱阳湖洲滩优势植物种群的分布格局. 湿地科学, 2011, 9(1): 19-25.

[21] 葛 刚, 李恩香, 吴和平等. 鄱阳湖国家级自然保护区的外来人侵植物调查. 湖泊科学, 2010, 22 (1) : 93-97. DOI 10. $18307 / 2010.0113$.

[22] 叶 春, 赵晓松, 吴桂平等. 鄱阳湖自然保护区植被生物量时空变化及水位影响. 湖泊科学, 2013, 25(5): 707714. DOI 10. 18307/2013. 0512.

[23] Dronova I, Gong P, Wang L. Object-based analysis and change detection of major wetland cover types and their classification uncertainty during the low water period at Poyang Lake, China. Remote Sensing of Environment, 2011, 115(12): 3220-3236.

[24] Dronova I, Gong P, Clinton NE et al. Landscape analysis of wetland plant functional types: The effects of image segmentation scale, vegetation classes and classification methods. Remote Sensing of Environment, 2012, 127: 357-369.

[25] Wang L, Dronova I, Gong P et al. A new time series vegetation-water index of phenological-hydrological trait across species and functional types for Poyang Lake wetland ecosystem. Remote Sensing of Environment, 2012, 125: 49-63.

[26] Zhang Q, Xiao M, Singh VP et al. Max-stable based evaluation of impacts of climate indices on extreme precipitation processes across the Poyang Lake basin, China. Global and Planetary Change, 2014, 122 : 271-281.

[27] Zhao X, Stein A, Chen XL. Monitoring the dynamics of wetland inundation by random sets on multi-temporal images. Remote Sensing of Environment, 2011, 115(9): 2390-2401.

[28] 张明伟. 基于 MODIS 数据的作物物候期监测及作物类型识别模式研究 [学位论文]. 武汉: 华中农业大学, 2006.

[29］林忠辉, 莫兴国. NDVI 时间序列谐波分析与地表物候信息获取. 农业工程学报, 2006, 22(12) : 138-144.

[30] 左丽君, 张增祥, 董婷婷等. MODIS/NDVI 和 MODIS/EVI 在耕地信息提取中的应用及对比分析. 农业工程学报, 2008, 24(3): 167-172.

[31] 王 丹, 姜小光. 利用 NOAA 数据分析中国地区植被覆盖变化周期. 中国图象图形学报, 2006, 11(4): 516-520.

[32] 张 霞, 孙 点, 张 兵等. 基于 MODIS 植被指数时间谱的华北平原土地覆盖分类. 农业工程学报, 2007,22 (12): 128-132.

[33］于信芳, 庄大方. 基于 MODIS NDVI 数据的东北森林物候期监测. 资源科学, 2006, 28(4) : 111-117.

[34] 梁守真, 邢前国, 施 平等. 山东省典型地表覆被 NDVI 时间序列谐波分析. 生态学杂志, 2011, 30(1): 59-65.

[35] 叶 春, 刘元波, 赵晓松等. 基于 MODIS 的鄱阳湖湿地植被变化及其对水位的响应研究. 长江流域资源与环境, 2013, 22(6): 705-712.

[36] 叶 春, 吴桂平, 赵晓松等. 鄱阳湖国家级自然保护区湿地植被的干旱响应及影响因素. 湖泊科学, 2014,26 (2) : 253-259. DOI 10. 18307/2014. 0212. 